\title{
FIGURAÇÕES DE SOBREVIVÊNCIA EM PRIMO LEVI. DIÁLOGOS COM NORBERT ELIAS
}

Andréa Borges Leão ${ }^{\mathrm{I}}$

Antonio Cristian Saraiva Paiva ${ }^{I I}$

\section{RESUMO}

Em meio às figurações sociais que moldam a vida dos indivíduos, o escritor italiano Primo Levi, deportado para Auschwitz, em 1944, se perguntou: "É isso é um homem?". Levi conseguiu sobreviver no trabalho da escrita de testemunho, embora não tenha escapado ao discurso que incorpora o indivíduo na consciência do mal. Ou, às práticas históricas de enunciação que criam a figura do judeu no plano da condenação moral como pessoa que tem um preço, portanto, escravizada. $\mathrm{Ou}$, aos impactos da crença e propaganda nazista no psiquismo humano. Escolheu um outro modo possível de dar fim ao seu trauma. Neste artigo, convidamos o sociólogo alemão Norbert Elias, assim como outros pensadores sociais, para desvelar as figurações de sobrevivência na narrativa de Primo Levi. As categorias analíticas da sociologia eliasiana utilizadas na interpretação de $A$ Tabela Periódica, o entrelaçamento de relações no mapa da existência, oferecem pistas de decifração do que o corpo e o coração de cientista escritor não conseguiram escapar.

\begin{abstract}
Amongst social figurations which shape the life of individuals, the Italian writer Primo Levi, deported to Auschwitz in 1944, asked himself: "Is this a man?". Levi managed to survive in the work of writing testimony, although he did not escape the speech that incorporates the individual in the evil consciousness. Nor the historical practices of enunciation that create the figure of the jew in the sphere of moral condemnation as a person who has a price, therefore, is enslaved. Nor the impacts of creed and Nazi propaganda in the human psyche. He chose another possible way to end his trauma. In this article, we invited the German sociologist Norbert Elias, as well as others social thinkers, to unfold the survival figurations in the narrative of Primo Levi. The analytical categories of eliasian sociology used in the interpretation of The Periodic Table, the interweaving of relations in the existence maps offer decoding clues of what the body and the heart of a scientist writer were not able to escape.
\end{abstract}

I Universidade Federal do Ceará, Fortaleza, Ceará, Brasil.
II Universidade Federal do Ceará, Fortaleza, Ceará, Brasil.

\section{PALAVRAS-CHAVE:}

Figurações de sobrevivência; ciência e civilização; escritas de si.

\section{KEYWORDS}

Survival figurations; science and civilization; self writing. 


\section{1.}

O projeto intelectual de Norbert Elias tem como fundamento as mútuas dependências entre sociogênese e psicogênese, entre as formações psíquicas dos indivíduos e as formações históricas das sociedades. $\mathrm{O}$ mesmo princípio analítico do entrelaçamento entre as duas dimensões da integração social é apresentado na ultrapassagem da oposição entre as estruturas sociais e estruturas naturais (ELIAS, 2018). As passarelas e pontes entre as três dimensões da socialização do indivíduo podem oferecer uma chave de interpretação dos dispositivos construídos por Primo Levi na narrativa, por exemplo, que elegemos para ilustrar a análise, A Tabela Periódica. Afinal, trata-se de um narrador cuja estrutura da personalidade vai sendo construída no curso de uma trajetória profissional altamente marcada pelo pertencimento racial e, por conseguinte, pela inscrição reativa em um momento singular do longo processo de civilização europeu. A escrita de Primo Levi orienta o seu destino autoral por figurações que compõem a dinâmica da ascensão e declínio tanto do nacional-socialismo, na Alemanha, quanto do fascismo, na Itália.

Norbert Elias, por toda a vida, dirigiu a atenção aos problemas do equilíbrio nas relações sociais. O equilíbrio que mais o fascinava era o que regulava as forças de controle exteriores e as forças de controle interiores aos indivíduos. As convergências entre a sua trajetória e a de Primo Levi revelam três forças atuantes nos destinos dos que se viram na contingência do exílio, da resistência e do testemunho do nazismo: forte reivindicação autoral, o desenraizamento e o estabelecimento de algum tipo de laço com os intelectuais de seu tempo. Os desvios de rotas e as bruscas interrupções das carreiras e o anonimato por longo intervalo não os impediram de manter o equilíbrio entre as três forças.

Norbert Elias descreveu um movimento entre a sociologia, a biologia, a psicologia social e a psicanálise, obtendo tardiamente o reconhecimento profissional da sua obra. De modo aproximado, Primo Levi confidencia ao escritor Philip Roth (1994, p. 239) o sentimento de perda por não ter se tornado um cientista, a guerra e o Lager o impediram, levando-o ao trabalho mais técnico como químico.

A obra do sociólogo, elaborada no curso do século $X X$, teve a propriedade de se autorregular, atualizar e prolongar em variadas classificações temáticas, ajustando-se aos novos desafios e provações teóricas das formações sociais modernas, dentre elas a Alemanha nazista. Ambos, Elias e Levi, "civilizados demais", como diria Philip Roth (1994, p. 237), pensadores contumazes, observadores que sabiam regular os pesos 
na balança do envolvimento e do distanciamento em relação aos horrores do Holocausto, são inseparáveis da figura do sobrevivente. Cientistas sobreviventes, como diria Roth, testemunharam o mesmo tempo social como observadores em movimento e com a curiosidade de naturalistas em meio a desordem, perseguição e devastação da guerra.

Norbert Elias nasceu no dia 22 de junho de 1897, na cidade alemã de Breslau. Elias viveu, portanto, sua juventude no período de ascensão do nacional-socialismo e testemunhou a chegada de Adolf Hitler ao poder. Como era de confissão judaica, isso significou a contingência da partida. Após os estudos inacabados de medicina, o encontro com a sociologia na Universidade de Heidelberg, as aulas de Alfred Weber e Karl Mannheim, e a ida a Frankfurt onde escreveu sua tese de habilitação sobre a sociedade cortesão francesa do século XVII, Elias tomou o caminho do exílio. A universidade encontrava-se sob o controle nazista $\mathrm{O}$ país escolhido, EM 1933, foi a França, após uma tentativa na Suíça. França e Suíça não corresponderam às expectativas do jovem sociólogo. Norbert Elias seguiu, então, para Londres (ELIAS, 2016).

Ao chegar à Inglaterra, passou por uma experiência marcante, a internação, por oito meses, em um campo de refugiados situado na Ilha de Mann, o Central Camp Douglas. Na primavera de 1940, período em que Elias acabara de adquirir um posto de assistente na London School of Economiscs, em Cambridge, a Inglaterra era um país em guerra. Enquanto os homens ingleses na idade de 18 a 45 anos eram obrigados a entrar no exército, os estrangeiros que haviam fugido do nazismo - a grande maioria judeus alemães e austríacos - eram enviados aos campos de internação a fim de realizarem um aprendizado da língua e uma adaptação à vida nacional. Temia-se que os imigrantes se constituíssem uma ameaça à coesão nacional. Instaurava-se, assim, uma relação mutuamente tensa entre estabelecidos ingleses e imigrantes empurrados para as margens, entre novos e velhos residentes da nação. ${ }^{1}$

Não se pode deixar de observar o fato de que a rotina de relações e hierarquias dos universos sociais de origem dos refugiados era bravamente mantida no campo. Apesar da contingência de deixar os pertences e bens para trás, as famílias mais ortodoxas organizavam escolas de teologia e hebraico. Elias, ele mesmo, não se desfez da cultura acadêmica alemã e acabou ministrando cursos sobre história da arte, psicologia social, psicanálise e sociologia. Daí, o sentimento ambivalente em relação ao internamento: aproveitou a oportunidade para aprender inglês.

David Rotman (2005, p. 166-7) interroga-se sobre as repercussões do internamento na carreira dos refugiados e as posteriores condições de

\footnotetext{
${ }^{1}$ David Rotman, partindo da correspondência de Elias no período de internamento, realiza um estudo detalhado sobre a experiência no Campo e o desenvolvimento da trajetória intelectual do sociólogo.
} 
socialização no país de acolhimento, o que quer dizer, o convívio com os britânicos. De acordo com Rotman, esta experiência explica as disposições mentais de Norbert Elias, indicando as condições de sua socialização na Inglaterra. Devido a seu forte capital social de relações intelectuais, Elias acabara tornando-se um estabelecido em uma população de marginais. Esta posição ajuda a entender suas disposições contraditórias, o sentimento de estranhamento atrelado a autoconfiança e o fato de jamais ter renunciado às suas ambições.

É realmente digno de nota o modo como, na concepção do sociólogo, a dominação entre os grupos sociais, seja na forma de tensões e concorrências abertas ou de disputas veladas, não invalida as dependências mútuas. Ao contrário, as interdependências se estruturam nas situações de dominação e nas lutas de poder. Graças aos professores e intelectuais de Frankfurt também exilados que intervieram a seu favor junto às autoridades inglesas e graças ao apoio das várias associações e comitês de ajuda exteriores, Elias não passou muito tempo em Camp Douglas. Naturalizou-se cidadão inglês em 1952, no mesmo ano em que participou com S. H. Foulkes da fundação do Group Analytic Society (DELUERMOZ, 2012, p. 17).

Elias demonstrou uma potente força moral para resistir à discordância, ou à incompatibilidade, entre o sentimento interior de seu próprio valor e a dificuldade de se ver reconhecido por seus pares. Precisou trabalhar duro e tenazmente para realizar seus desejos de infância: tornarse professor universitário e cientista social. Durante a aposentadoria, em 1962, ainda conseguiu ocupar um posto de Professor Emérito na Universidade de Gana, onde permaneceu por dois anos estudando arte africana. No retorno de Gana, Elias ocupou o posto de Professor Visitante na Alemanha e, deste então, fez inúmeras viagens entre a Alemanha e a Holanda. Em 1984, se instala definitivamente em Amsterdam. Por este tempo, o reconhecimento havia chegado e seus livros ganhavam o mundo em traduções. Em 1977, recebe o Prêmio Adorno e, em 1987, o Prêmio Amalfi de Sociologia, falecendo aos 93 anos, em 1990.

Nos relatos autobiográficos do sociólogo, destaca-se uma cena na cafeteria de Tottement Court Road, em 1938, que guarda a força do testemunho. Seus pais, Herman e Sophia, visitavam o filho único que insistia, nesta ocasião, na vinda definitiva deles para a Inglaterra. Ainda que o mundo civilizado não imaginasse o que estaria por vir, Herman responde a Elias, em alemão, com ternura e confiança: "mas tudo isso é um absurdo. Eu jamais fiz nada de mal ao longo da minha vida na Alemanha. O que os nazistas poderiam fazer a mim?" (ELIAS, 2016, p. 75). A família de comerciantes burgueses se formara no Império e conhecera o estado de direito, jamais transgredira qualquer lei ou moral, dizia o pai ao filho. Herman faleceu em Breslau, em 1940, sua cidade natal, Sophia foi 
assassinada em Auschwitz, em 1941, três anos antes da chegada de Primo Levi.

O colapso da civilização que traduz o movimento nacional-socialista alemão assentava-se na crença da impureza racial de grupos inferiores contraposta à superioridade ariana. A eficácia de tal sistema era medida na opinião pública pelo seu poder de realização e destruição. Formas bárbaras e racionais de matar foram postas em prática. Por conseguinte, o cumprimento dos objetivos do sistema de crenças nazistas deveria proporcionar ao grupo portador alto grau de satisfação imediata (ELIAS, 1997, p. 279). Ainda que pudesse ser visto como mera fantasia ou meio para um fim racional. Para Norbert Elias, a ideia de civilização enquanto sincronia construída na longa duração entre o controle externo e o interno aos indivíduos, a partir daí, deixaria de ser concebida como atributo natural das nações europeias.

Um meticuloso trabalho de sublimação dos afetos foi necessário para que Elias examinasse os resultados da modelação secular do habitus nacional alemão e escrevesse um livro sobre o colapso civilizatório que tirou a vida de sua mãe, Sophia Elias, provavelmente envenenada por gases letais. Em Norbert Elias, o sentimento de estranhamento atrelava-se a autoconfiança e ao fato de jamais ter renunciado às suas ambições. Escrever sobre a dinâmica civilizatória alemã implicava em esforços de distanciamento que visavam não apenas a controlar o processo de conhecimento da realidade imediata, mas também ao investimento na autorreflexão necessária à construção da memória. Na mesma perspectiva, Philippe Mesnard (2019, p. 24) chama a atenção para as armadilhas do olhar retrospectivo sobre o testemunho na escrita de Primo Levi. A função do testemunho não se reduziria, em Levi, a militância na construção da memória. Ora, em ocasiões de debates públicos nas escolas e meios de comunicação de massa, como rádio e televisão, em que fazia uso da palavra falada, Levi podia até assumir a função do testemunho factual, o que não invalidava o ponto de vista meticuloso do cientista que atravessa o conjunto de sua obra escrita. Mesnard (2019, p. 25) observa que, a partir dos anos 1970, a narrativa escrita de Primo Levi opera um deslocamento na posição do testemunho. Ou melhor, em um testemunho em movimento. Com o crescimento dos ataques terroristas e ameaças à democracia em vários países, o escritor, vendo-se confrontado às fragilidades e ameaças de novos dramas humanos, assume uma voz cética e desencantada.

Se há uma invariância nos relatos de Primo Levi é o da incorporação do indivíduo de confissão ou origem judaica na consciência do mal, de uma condenação moral presente, sobretudo, na memória da juventude. $\mathrm{O}$ narrador soma a isso a mediação das lembranças da guerra e marcas do genocídio. 


\section{A Tabela Periódica. Ciência e civilização}

A teoria da civilização de Norbert Elias conduz a um debate fecundo com a produção sociológica do século XX. Ao se posicionar na esteira dos fundadores da sociologia, Spencer, Comte e Marx, para os quais as dinâmicas e estruturas sociais devem ser apreendidas em seus processos de evolução, mudança e transformação, Norbert Elias retoma o princípio da historicidade dos objetos de investigação sociológica. Usando a imagem de uma clausura, chama a atenção para uma tendência dos sociólogos do século XX para o estudo de objetos situados cronologicamente no presente, desconectados de suas forças motrizes de desenvolvimento econômico, político e cultural, e da perspectiva da explicação processual se já histórica ou memorialista (ELIAS, 2003).

Para a teoria da civilização, as situações de interação social apresentam-se em constante movimento e os códigos de conduta vão se deslocando na direção das mudanças no equilíbrio entre as formas do controle social externo e as formas de controle interior aos indivíduos. $\mathrm{O}$ fundamento da sociologia consiste na elaboração de um modelo de análise capaz de apreender os processos sociais de longo prazo, articulando transformações das estruturas da personalidade - a psicogênese dos comportamentos individuais, às transformações das estruturas políticas e monopólios de poder - a sociogênese do estado. Essas articulações no domínio das exigências e controles civilizatórios desconstroem os esquemas intelectuais das oposições binárias que orientam um tipo específico de conhecimento sociológico, superando falsas dicotomias, a exemplo da que separa o estudo dos indivíduos do estudo das sociedades.

$\mathrm{O}$ modelo de interpretação construído por Elias permite o estabelecimento de um amplo e detalhado quadro comparativo entre sociedades distantes no tempo e no espaço, levando-nos a indagar as possibilidades de equivalências entre diferentes processos de civilização. O que nos vincula, ainda que remotamente, às formalidades da existência, aos padrões do convívio social dos cortesãos franceses, ingleses e alemães, no século anteriores aos rumos descritos pelas mudanças sociais e psíquicas de longo prazo.

Elias começa nos alertando que os modelos processuais não são sistemas rígidos e invariantes como pensava Talcoott Parsons (ELIAS, 2008), mas ferramentas de explicação construídas na observação de cadeias sociais flexíveis, altamente variáveis e imprevisíveis em suas combinações. Os modelos, no entanto, não operam apenas com propriedades comuns a cada uma das interdependências humanas. Eles perdem a validade com a passagem do tempo e com as mudanças de uma forma de interação a outra. A coerência do modelo não descarta os objetos aos quais se aplica. Esses objetos tampouco se organizam como grupos sociais voltados para o melhoramento progressivo de suas funções. Os processos sociais podem 
ser reversíveis e as experiências humanas perdidas, o que se torna evidente em tragédias e terrores das dimensões do Holocausto.

Em 11 de abril de 1987, Primo Levi, testemunho do colapso da civilização ocidental, narrador das figurações de sobrevivência no campo de Auschwitz, deu um fim à própria vida. Levi nasceu no dia 31 de julho de 1919, em Turim, no seio de uma família de judeus piemonteses. Durante os estudos ginasiais no Liceu D'Azeglio, onde já despontara seu interesse pelas disciplinas de biologia e química, entrou em contato com professores ilustres e destacados na resistência ao fascismo, como Norberto Bobbio. Em 1937, matricula-se no curso de química da Faculdade de Ciências da Universidade de Turim. Por essa época, o governo fascista da Itália impunha as leis raciais interditando aos jovens judeus os estudos universitários. Como Levi já havia se inscrito na graduação, prosseguiu os estudos graduando-se em 1941 com distinção e louvor, ainda que a menção "de raça judia" estivesse marcada no seu diploma. Após a experiência de trabalho em condições precárias em uma mina de amianto e, posteriormente, em uma fábrica suíça de medicamentos, Primo Levi participa de grupos antifascistas. Em 1943, quando a Itália é ocupada pela Alemanha, é preso com outros companheiros e deportado para o campo de Carpi-Fòssoli. Deste, segue em trem ferroviário para o campo de Auschwitz, na Polônia. De fevereiro de 1944 a janeiro de 1945 começa para ele a experiêmcia sobre a qual, anos após, declara que não bastaria narrar, mas libertar-se interiormente (LEVI, 2013).

A história editorial dos livros de Primo Levi não correspondeu à envergadura e originalidade de cada um deles. Precisaram de intervalos consideráveis para publicação e reconhecimento de crítica e público. Guardadas as devidas proporções, esse é um outro ponto biográfico em comum com Elias. Ilustrativo é o hoje consagrado livro Se isso é um homem, escrito e reescrito entre 1946 e 1947, e que teve uma primeira edição após diversas correções propostas na rejeição de Natália Ginzburg da prestigiosa Editora Einaudi. Décadas após, em 1963, esta editora publica $A$ trégua, que agrada a crítica literária e traz a orelha escrita por Ítalo Calvino. Este livro que narra o percurso da libertação dos prisioneiros do campo de Auschwitz e a longa saga de retorno a Itália ganha um prêmio literário em Veneza, consagrando Primo Levi como memorialista.

Em 1975, fazendo uso de metáforas a partir da tabela de organização dos elementos químicos de Mendeleev, é publicado o livro A Tabela Periódica. Nele, Primo Levi inventa uma forma literária com textos curtos reunidos por um fio cronológico que acompanha a um só tempo a formação profissional e o relato nas figurações de sobrevivência anteriores e posteriores à guerra. A construção de um universo simbólico de interdependências entre os elementos da natureza descobertos nas relações com parentes, amigos e antagonistas vai deslizando entre a descrição científica e a imaginação ficcional. O capítulo de abertura conta a sua 
história familiar, judaica de origem piemontesa, formada por figuras que apresenta como inertes (pouco dadas a reações, a maneira de certos gases) suaves e marcadas pela prudência, tal qual o elemento Argônio. Aí é narrada a lembrança da infância, dos avós, tios e primos. No capítulo seguinte, o autor conta a sua estreia no laboratório de química, como a lei das proporções leva-o à descoberta do hidrogênio. Como o Zinco é um metal aborrecido no capítulo a ele consagrado aparece a figura do Professor P. que ministrava aulas de química orgânica e inorgânica. A iniciação científica do narrador se dá pela preparação do sulfato de zinco, o encontro com a estudante cristã Rita e a reflexão sobre o atributo da impureza concedido à raça judia, isolando-o dos demais colegas “(...) sou a impureza que faz reagir o zinco, sou o grão de sal e de mostarda. A impureza, certamente: porque justamente naqueles meses se iniciava a publicação de $A$ defesa da raça, de pureza se falava muito, e eu começava a ficar orgulhoso de ser impuro" (LEVI, 1994, P. 41). O contato amoroso com Rita não foi adiante, mas a pequena vitória de entrelaçar o braço no dela o encheu de confiança e de um sentimento de ter vencido uma batalha "pequena mas decisiva, contra a escuridão, o vazio e os anos hostis que viriam" (p. 42). Por um breve momento, o casal improvável compunha uma possível figuração de sobrevivência.

Não se podem descartar dispositivos comuns às experiências individuais na formação das figurações sociais, como as tensões nos padrões de autorregulação da vida afetiva entre os indivíduos, entre os indivíduos e os grupos e entre os grupos e a sociedade. Nas entrevistas autobiográficas, Levi evoca a timidez com relação as mulheres como um traço de sua personalidade difícil de lidar e que já o levara a pensar em suicídio. $\mathrm{Ou}$, seriam os impactos da realidade na sua vida psíquica? $\mathrm{O}$ elemento Ferro narra a amizade e excursões pelas montanhas na companhia de Sandro, futuro combatente do Partido da Ação capturado pelos fascistas em 1944. Os amigos traçam, na descoberta da natureza e no experimento da sobrevivência, verdadeiro mapa da existência. Os capítulos sobre o Níquel e o Fósforo confrontam o narrador ao exercício coletivo da profissão de licenciado em química, em condições tão precárias quanto sinistras. $\mathrm{O}$ contato íntimo com a matéria e o isolamento social a que se vira constrangido, na mina de extração de amianto, pela geografia e vigência da lei racial, só se equiparam em importância ao novo emprego na fábrica suíça de medicamentos onde reencontra Giulia, colega não judia de faculdade a quem "uma nuvem, um sopro, um lance de dados, nos desviaram por dois caminhos divergentes que não eram os nossos (p. 119). Giulia, mais uma ligação que não se efetiva, deixa a fábrica e a cidade de Milão para ir ao encontro do noivo. O narrador se volta para a escrita de poemas (tinha planos de escrever a saga solene do átomo de carbono) e a militância em um grupo de rapazes e moças antifascistas. Corria o ano de 1942, A inexperiência e o alheamento dos jovens turinenses desenraizados 
em Milão, resistentes sob o frio e o bombardeio dos ingleses, atrai justo um agente das forças fascistas, um infiltrado que acaba traindo-os e delatandoos na noite de 13 de dezembro de 1943: "Daquilo que nesses mesmos meses ocorria em toda a Europa ocupada pelos alemães, na casa de Anne Frank em Amsterdã, na fossa de Babi Yar perto de Kiev, no gueto de Varsóvia, em Salônica, em Paris, em Lídice: desta pestilência prestes a nos engolfar não chegara até nós nenhuma notícia precisa, apenas alusões vagas e sinistras (...)" (LEVI, 1974, p. 129). Esse capítulo é intitulado Ouro. Nele, o narrador descobre o fascismo não apenas como desgoverno burlesco e improvisado, testemunha a ocupação da Itália, é capturado, espancado junto aos companheiros, isolado, interrogado e, ainda com a metáfora do metal ouro, é deportado para um campo de concentração. Os seguintes, obedecendo a ordem periódica dos elementos da tabela, contam a experiência como prisioneiro de n. 174517, sua inserção na ordem do Lager. Primo Levi trabalhou no laboratório de químico em Auschwitz de onde roubara alguns gramas de ácido graxo para matar a fome descrevendo-o detalhadamente no capítulo Estanho. No final da guerra, de volta à Itália, reencontra companheiros de juventude. A condição judaica se impõe em todo o relato, a ponto de no capítulo final intitulado apropriadamente carbono a narrativa se encerrar com o ciclo de vida e morte de um átomo de carbono. A bela metáfora ilustrada pela fotossíntese clorofiliana aproxima mais ainda a química da literatura. A grande questão continua sendo: quem são os que me fizeram isso e por quais motivos o fizeram? $\mathrm{O}$ que deixa traços e abre feridas profundas que embaralham o presente e o passado.

Para Philippe Mesnard (2004, p. 15), nos relatos de Levi há uma correspondência entre as convenções da oralidade e as da escrita. Na obra do autor relatos e poemas são ligados pelo sofrimento, continua Mesnard. Em resposta a Giulio Nascimbeni, em 1984, Levi afirmara que os poemas vieram antes da escrita de $E$ isso um homem?, entre 1946 e 1947, no retorno à Itália. A leitura de sua obra leva a crer que poesia e relato, assim como o tratado sobre o sistema periódico e demais publicações técnicas sobre química constróem, cada um a seu modo, o ponto de vista do sobrevivente do qual, observa Philippe Mesnard (2004, p. 17), ele restou prisioneiro. Fortalecido por um disciplina interior provavelmente adquirida como matriz pré-reflexiva do mundo social no curso de sua formação familiar e escolar, o ponto de vista de Levi também foi o do cientista. O observador metódico instaurou um espaço público de transmissão da experiência vivída.

Com a lapidação da teoria da civilização e de seu projeto intelectual de síntese do estudo dos seres humanos em interdependências, Norbert Elias, movendo-se em zigue-zague, retorna à sua formação de origem e considera também a teoria da evolução como uma transversalidade à teoria da civilização. A exemplo dos estudos sobre o potencial biológico para a 
linguagem, nos homens, que de nada valeria se não fosse ativado pela aprendizagem. As estruturas orgânicas necessitam ser ativadas pela aprendizagem. Se os indivíduos são equipados pela natureza dependem da cultura para aprender. $\mathrm{E}$ a aprendizagem diz respeito à vida coletiva. $\mathrm{E}$ aqui chegamos ao projeto tridimensional de Elias (2018) que articula a evolução biológica das espécies, os processos sócio-históricos de longa duração e os processos de maturação psíquica dos indivíduos. A ligação entre sociologia e biologia, nos mostra a indissociabilidade entre as disciplinas, do modo como Primo Levi preencheu a literatura com uma valência aberta pela química, fazendo convergir domínios singulares e, até, epistemologicamente antagônicos, no enfrentamento de objetos e problemáticas em comum.

\section{Escrita de si. Subjetivação e testemunho}

Buscar as palavras para dizer a vida, para subjetivar afecções, despotências e emoções do corpo e da alma é trabalho singular e ao mesmo tempo demanda o apoio de redes de interdependência, carecendo de uma "confiança implícita em certas convenções linguísticas" da sociedade (ELIAS, 2001, p. 53), que torna mais estável a economia psíquica do relato autobiográfico. Podendo ser assim pensado como termômetro do trabalho de civilização, a mediação dos afetos fortes pelas convenções sociolinguísticas vem em socorro do indivíduo na costura biográfica entre narrativa, relato científico e emoções. Em momentos de colapso no modelo de civilização, continuemos com o argumento de Norbert Elias, com o vacilar de "padrões tradicionais de comportamento nas grandes situações de crise da vida humana", a tarefa de "encontrar a palavra e o gesto certos, portanto, sobra para o indivíduo" (p. 35), equivocando as capacidades de dizer, mergulhando o relato na dimensão do trauma.

Judith Butler identifica uma "dialética negativa" no trabalho de autoconstituição do eu, por via do relato, apontando as tensões entre o "si mesmo" e o conjunto de normas sociopsíquicas: "Quando o "eu" busca fazer um relato de si mesmo, pode começar consigo, mas descobrirá que esse "si mesmo" já está implicado numa temporalidade social que excede suas próprias capacidades de narração; na verdade, quando o "eu" busca fazer um relato de si mesmo sem deixar de incluir as condições de seu próprio surgimento, deve, por necessidade, tornar-se um teórico social. A razão disso é que o "eu" não tem história própria que não seja também a história de uma relação - ou conjunto de normas". (BUTLER, 2015, p. 18).

Evocamos aqui a ideia da dobra (plis) e da constituição do forro, vinda da leitura deleuziana (DELEUZE, 1988) do trabalho de Michel Foucault sobre a relação consigo (rapport à soi), que nos ajuda a entender o permanente risco de "despossessão do eu", apontado por Butler, intrínseco no trabalho de relatar a si mesmo. A topologia da dobra e do forro seria 
uma alternativa para pensar a relação eu-outro de forma não-dicotômica, desfazendo a ideia do eu como casulo, como mônada encerrada em si mesma.

Tema que atravessa toda a obra de Foucault, a relação do sujeito com o discurso, a questão da escrita de si (écriture de soi) se inscreve nos estudos do filósofo sobre "as artes de si mesmo" e sobre as questões do governo e do cuidado de si e dos outros e pode nos ser útil para avançar metodologicamente sobre a relação entre o eu, a violência e o relato. No texto de 1983, Foucault avança a hipótese de que a escrita de si aparece como complementar às práticas ascéticas, como trabalho sobre os atos e sobre os pensamentos, numa anamnese solitária sobre a própria vida: a escrita toma o lugar dos companheiros de ascese, diz Foucault (1992, p. 130). A escrita é apresentada, nesse contexto, como "uma prova", "uma arma de combate espiritual", "ao trazer à luz os movimentos do pensamento, dissipa a sombra interior onde se tecem as tramas do inimigo" (p. 131). Pressupondo um espaço de interdependência, a escrita de si - o fato de escrever para si e para outrem - relaciona-se de perto com as práticas confessionais e com as meditativas, como esforço de domínio sobre os pensamentos ("exercício do pensamento sobre si mesmo que reativa o que ele sabe"). Há uma agonística implícita nesse trabalho de autoconstituição do eu, entendido como um treino de si: "deve-se meditar (meletan), escrever (graphein), treinar (gymnazein)" (p. 133). O que cabe à escrita é operar a transformação da verdade em ethos, e por aqui reencontramos a argumentação de Butler sobre a relação entre o relatar a si mesmo e a violência ética.

Mas antes de voltar a este ponto, prossigamos com Foucault, descrevendo as duas formas empregadas nas práticas de escrita com função etopoiética: os cadernos pessoais (os hypomnemata) e a correspondência. Os primeiros funcionavam como veículo de subjetivação do discurso (p. 137) e constituíam "uma memória material das coisas lidas, ouvidas ou pensadas" (p. 135), funcionavam como recoleção de um "logos fragmentário" e ligavam-se ao trabalho sobre si mesmo. Não funcionavam, porém, como uma hermenêutica de um eu oculto, a revelar, mas ligados a um modo de vida e a uma relação consigo baseados no ideal de uma autocracia, de um domínio de si: o papel da escrita, diz Foucault, é constituir um corpo: "a escrita transforma a coisa vista ou ouvida 'em forças e em sangue'"' (p. 143).

Junto com o caderno pessoal, Foucault aponta que as cartas seriam o outro tipo de prática de escrita de si com função etopoiética, ou seja, ligados ao trabalho de autoconstituição moral do eu. A carta atua junto àquele que escreve e àquele que lê. Escrever é aqui "mostrar-se, dar-se a ver, fazer aparecer o rosto próprio junto ao outro (p. 150), é um trabalho, "uma abertura de si mesmo que se dá ao outro" (p. 152). 
Foucault nos conduz à conclusão de que o que essas práticas de escrita de si nos revelam é a própria criação dessa dobra - a relação consigo mesmo (rapport à soi) - como um forro constituído a partir da subjetivação das forças do fora (dehors) que atravessam o corpo e a alma dos indivíduos, como treino pra dominá-las, espaço de cuidado e de assenhoramento de si. É assim que, para o filósofo, a escrita de si é a escrita da relação consigo (p. 153), produzindo um modelo de subjetivação baseado no cuidado de si, típico dos primeiros séculos de nossa era.

Na conferência Qu-est-ce qu'une vie bonne? Butler (2014) já havia chamado atenção de que ficaram excluídos dos privilégios desses exercícios de ocupar-se consigo mesmo e da cultura pública a eles relacionada o grande contingente humano constituído pelas crianças, mulheres, estrangeiros e escravos, privados do direito ao relato de si, cujas vidas eram vividas na zona de pouca visibilidade da vida privada, pouco consideradas pelos dispositivos éticos e subsumidos na violência das instituições sociais.

Voltamos à relação entre relato de si e violência, introduzindo a noção de vulnerabilidade (vulnerability) e do risco onipresente de violação (injury). Essa é a via pela qual Butler faz a crítica da soberania do sujeito e das estratégias biopolítica da modernidade, analisando as disposições emocionais relacionadas à repugnância, ao luto, à ansiedade e ao medo, a partir das experiências de violência arbitrária sofridas (no caso, a filósofa situa suas reflexões no pós 11 de setembro de 2001).

Embora partilhando enquanto seres humanos as condições "originárias" de desamparo e vulnerabilidade ("a percepção de que podemos ser violados, de que outros podem ser violados, de que estamos sujeitos à morte pelo capricho de outrem"), a autora demonstra que vivemos uma radical desigualdade na distribuição de vulnerabilidades, associadas ao risco de desumanização de sujeitos e populações e a uma distribuição desigual do luto pela perda de suas vidas. A questão ética fundamental passa a ser "quais vidas contam como vidas? (...) o que concede a uma vida ser passível de luto?" (2019, p. 40).

Afinal, qual vida conta como vida vivível, vida digna de relato? Quais vidas sucumbirão à desumanização, ao silêncio, à invisibilidade, sequer sendo dignas de serem reconhecidas enquanto vidas? Que mecanismos de regulação das identificações psíquicas e públicas são acionados nesse sistema de produção desigual de vulnerabilidade (p. 15)? Butler enxerga na noção levinasiana de rosto - entendido como uma figura comunicativa tanto da precariedade da vida quanto da interdição da violência (2019, p. 16) - um instrumento de insurreição e de aliança política. $O$ rosto, o luto, o relato: rastros que permitem combater a desrealização de indivíduos e suas biografias (nesse sentido, podemos entender a interrogação de Primo Levi: É isso um homem?).

A experiência da perda, do sofrimento, do luto, enquanto experiência de finitude e de vulnerabilidade que nos torna semelhantes, 
introduz "um senso de comunidade política complexa" (BUTLER, 2019, p. 43), induz um relato e uma transformação naqueles afetados: "O luto conservaria uma dimensão enigmática, uma experiência do não saber provocada pela perda do que não podemos compreender completamente (...) quando passamos pelo que passamos, algo sobre o que somos nós é revelado" (Idem, p. 42). O luto, a perda, a violência sofrida convocam, assim, o testemunho, o relato, um eu em trabalho de desidentificação do corpo e da alma violados. Convoca nossa habilidade de narrar permeadas pelo trabalho do tempo (DAS, 1999), do silêncio, da palavra, do afeto que vem do trauma, despossuindo o eu, relançando-o ao enigma do resíduo que não cessa de não ser dito... Tal como o trabalho do luto, de elaboração da perda, que sempre produz um umbigo, resto a dizer.

Dizer o trauma, a perda, poder relatar a si mesmo pressupõem condições sociais de corporificação e de individuação que permitam poder falar e poder ser ouvido, assim como habilidades narrativas que fazem fronteira com o percurso terapêutico. Ken Plummer, ao trabalhar com rupturas biográficas associadas a histórias de sofrimento, sobrevivência e de superação de traumas, confirma essa ideia de uma correlação entre cultura de narrativas e cultura terapêutica, correlação esta que amplia o léxico da cidadania (1995, p. 06). O trabalho de encontrar uma voz, achar as palavras para dizer, retrabalhar cenas e superar fraturas biográficas exige levar em conta os complexos processos sociais de produção e recepção das narrativas sobre si. Para Plummer, alguém que conta sua própria história desvela ações coletivas incorporadas em mundos sociais, envolvendo construções do eu, interações simbólicas e processos políticos. (1995, p. 17, p. 19). A elaboração dos sentimentos - especialmente a vergonha, a culpa e o medo, é um vetor fundamental de estabilização do eu e de produção de passarelas narrativas entre as experiências de dor e a sobrevivência psíquica.

O tema da relação entre permanência do eu e pertencimento social diante de experiências extremas é tema caro ao trabalho do sociólogo Michael Pollak. As noções de identidade ferida (identité blessée), gestão do indizível e sobrevida são fundamentais para trabalhar a questão da escrita de si na experiência concentracionária (POLLAK, 1990), abrindo-nos várias possibilidades analíticas.

Também as ideias de Boris Cyrulnik (2010) iluminam as sinuosas articulações entre dor, culpa e vergonha e o risco de uma crueldade aniquilante que não deixa espaço para o resto a dizer, obrigando o eu a uma posição culpada e melancólica de repetir o intolerável da cena traumática.

Cremos que esses apontamentos metodológicos podem servir-nos para abordar os textos de Primo Levi a partir desse olhar de uma sociologia das narrativas do eu, permitindo-nos desvelar as articulações entre escrita de si, relato e figurações de sobrevivência. 


\section{Referências bibliográficas}

BUTLER, Judith. Vida precária: os poderes do luto e da violência. Belo Horizonte: Autêntica, 2019.

BUTLER, Judith. Relatar a si mesmo: crítica da violência ética. Belo Horizonte: Autêntica, 2015.

BUTLER, Judith. Qu'est-ce qu'une vie bonne? Paris: Payot, 2014.

CYRULNIK, Boris. Mourir de dire: la honte. Paris: Odile Jacob, 2010.

DAS, Veena. "Fronteiras, violência e o trabalho do tempo": alguns temas wittgensteinianos. Revista Brasileira de Ciências Sociais, v. 14.

DELUERMOZ, Quentin. Norbert Elias (sous la direction de). Paris: Tempus Perrin, 2012.

DELEUZE, Gilles. Foucault. São Paulo: Brasiliense, 1988.

ELIAS, Norbert. A solidão dos moribundos, seguido de Envelhecer e morrer. Rio de Janeiro: Jorge Zahar, 2001.

ELIAS, Norbert. "O processo civilizador". Ed. Formação do Estado e civilização, v. II. Rio de Janeiro: Jorge Zahar Editor, 1993.

ELIAS, Norbert. Os alemães. A luta pelo poder e a evolução do habitus nos século XIX e XX. Rio de Janeiro: Jorge Zahar Editor, 1997.

ELIAS, Norbert. J'ai suivi mon propre chemin. Un parcours dans le siècle: propos autobiographiques, Respect et critique: discours de réception du prix Adorno. Paris: Les Éditions Sociales, 2016.

ELIAS, Norbert. « Les êtres humains et leurs émotions: essai de sociologie processuelle ». In: Sensibilités. Histoires E Sciences Sociales. Controverses sur l'émotion. Neurosciences et sciences humaines. Paris: Anamosa, 2018. FOUCAULT, Michel. "A escrita de si". In: O que é um autor? Lisboa: Vega, 1992.

LEVI, Primo. A Tabela Periódica. Rio de Janeiro: Relume Dumará, 1994.

LEVI, Primo. Se isso é um homem. Córdova: Dom Quixote; Leya, 2013.

MESNARD, Philippe. "Primo Levi, du rapport sur Auschwitz à la littérature ». Dits et inédits, 2004. Disponível em: http://www.revuetexto.net/1996-2007/Inedits/Inedits.html

MESNARD, Philippe. «Primo Levi, un témoin en mouvement». Mougel, Célia e Khouadja, Mona. Mémoires, 2019, n. 3, p. 24-5. Disponível em: https://www.cairn.info/revue-memoires-2019-3-page-24.htm

PLUMMER, Ken. Telling sexual stories: power, change and social worlds. Londres: Routledge, 1995.

POLLAK, Michael. L'expérience concentrationnaire: essai sur le maintien de l'identité sociale. Paris: Métailié, 1990.

ROTH, Philip. "Philip Roth entrevista Primo Levi”. In: A Tabela Periódica. Rio de Janeiro: Relume Dumará, 1994.

ROTMAN, David. "Trajectoire intellectuelle et expérience du camp »: Norbert Elias à l'île de Man. Revue d'histoire moderne E contemporaine, 2005, 


\section{n. 52, p. 148-68. Disponível em: https://www.cairn.info/revue-d-histoire- moderne-et-contemporaine-2005-2-page-148.htm}

Recebido em 5 de agosto de 2020

Aprovado em 28 de setembro de 2020

Andréa Borges Leão é professora do Departamento de Ciências Sociais, do Programa de Pósgraduação em Sociologia da Universidade Federal do Ceará e pesquisadora do CNPq. Escreveu Brasil em imaginação. Livros, impressos e leituras infantis (2012), fruto de sua tese de doutorado na Universidade de São Paulo, e Norbert Elias e a Educação (2007). Publicou capítulos em coletâneas, artigos em periódicos e organizou dossiês temáticos sobre sociologia da literatura, da circulação cultural e da edição literária. Escreveu os capítulos "Elias and Literature": psychogenesis of Brazil in French books for young people, em Norbert Elias and Empirical Research (2014), e o "O Brasil na edição francesa oitocentista", em Deslocamentos e Mediações. A circulação transatlântica dos impressos (1789-1914) (2018). Contato: aborgesleao@gmail.com

ORCiD: https://orcid.org/0000-0001-8404-6767

Antonio Cristian Saraiva Paiva é professor associado do Departamento de Ciências Sociais, do Programa de Pós-Graduação em Sociologia da Universidade Federal do Ceará, bolsista de produtividade do CNPq e coordenador do Núcleo de Pesquisas sobre Sexualidade, Gênero e Subjetividade (NUSS) da UFC. Escreveu os livros Reservados e invisiveis: o ethos íntimo das parcerias homoeróticas (2007) e Sujeito e laço social: a produção de subjetividade em M. Foucault (2000). Organizou a coleção Gapuia: Sociologia em pesquisas $\mathcal{E}$ teses (2017) e o livro Estilísticas da sexualidade (2006). Publicou diversos capítulos de coletâneas e artigos em periódicos nos estudos sobre geração, corpo, saúde, sexualidade e escrita de si. Contato: cristianspaiva@ufc.br

ORCiD: https://orcid.org/0000-0001-6478-1297 